\title{
Graphene Decorated with Iron Oxide Nanoparticles for Highly Sensitive Interaction with Volatile Organic Compounds ${ }^{+}$
}

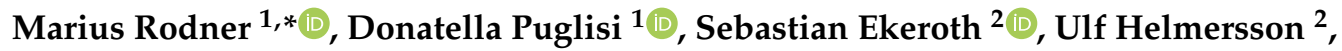 \\ Ivan Shtepliuk ${ }^{3}{ }^{(0)}$, Rositsa Yakimova ${ }^{3}$, Andreas Skallberg ${ }^{4}$, Kajsa Uvdal ${ }^{4}$, Andreas Schütze ${ }^{5}$ (i) \\ and Jens Eriksson ${ }^{1}$ \\ 1 Applied Sensor Science Unit, IFM, Linköping University, 58183 Linköping, Sweden; \\ donatella.puglisi@liu.se (D.P.); jens.eriksson@liu.se (J.E.) \\ 2 Plasma \& Coatings Physics Division, IFM, Linköping University, 58183 Linköping, Sweden; \\ sebastian.ekeroth@liu.se (S.E.); ulf.helmersson@liu.se (U.H.) \\ 3 Semiconductor Materials Division, IFM, Linköping University, 58183 Linköping, Sweden; \\ ivan.shtepliuk@liu.se (I.S.); rositsa.yakimova@liu.se (R.Y.) \\ 4 Division of Molecular Surface Physics \& Nanoscience, IFM, Linköping University, 58183 Linköping, Sweden; \\ andreas.skallberg@liu.se (A.S.); kajsa.uvdal@liu.se (K.U.) \\ 5 Lab for Measurement Technology, Department of Systems Engineering, Saarland University, \\ 66041 Saarbrücken, Germany; schuetze@lmt.uni-saarland.de \\ * Correspondence: marius.rodner@liu.se; Tel.: +46-700-896785 \\ + This paper is an extended version of the conference paper: Iron Oxide Nanoparticle Decorated Graphene for \\ Ultra-Sensitive Detection of Volatile Organic Compounds. In Proceedings of the EUROSENSORS 2018, Graz, \\ Austria, 9-12 September 2018.
}

Received: 29 January 2019; Accepted: 19 February 2019; Published: 22 February 2019

check for updates

\begin{abstract}
Gases, such as nitrogen dioxide, formaldehyde and benzene, are toxic even at very low concentrations. However, so far there are no low-cost sensors available with sufficiently low detection limits and desired response times, which are able to detect them in the ranges relevant for air quality control. In this work, we address both, detection of small gas amounts and fast response times, using epitaxially grown graphene decorated with iron oxide nanoparticles. This hybrid surface is used as a sensing layer to detect formaldehyde and benzene at concentrations of relevance (low parts per billion). The performance enhancement was additionally validated using density functional theory calculations to see the effect of decoration on binding energies between the gas molecules and the sensor surface. Moreover, the time constants can be drastically reduced using a derivative sensor signal readout, allowing the sensor to work at detection limits and sampling rates desired for air quality monitoring applications.
\end{abstract}

Keywords: epitaxial graphene; metal oxide nanoparticle; gas sensor; volatile organic compounds; benzene; formaldehyde; derivative sensor signal; air quality sensor

\section{Introduction}

Several toxic air pollutants in more than $80 \%$ of the urban areas where air pollution is monitored exceed the World Health Organization's (WHO) recommended safe exposure levels. Poor air quality has been associated with several negative health aspects ranging from less severe conditions, such as skin and eye irritation, to more acute respiratory problems, cancer, or death. Air pollution has been estimated to cause 8 million annual deaths and to financially burden the European region by about 1.6 trillion US dollars per year [1,2]. 
Air quality (AQ) monitoring and control using extremely sensitive sensors are crucial from the viewpoint of preventing further deaths and diseases correlated with toxic air substances. However, commercial sensors/instruments available today are either large, expensive, and complex or small but limited by poor selectivity, sensitivity, and a slow sampling rate [3]. In addition, there are no commercially available sensors with sufficiently low detection limits to monitor carcinogenic volatile organic compounds (VOCs), such as formaldehyde $\left(\mathrm{CH}_{2} \mathrm{O}\right)$ and benzene $\left(\mathrm{C}_{6} \mathrm{H}_{6}\right)$, at levels of relevance to human health. Benzene is a genotoxic aromatic compound, especially associated with leukemia. There are no safe exposure limits for $\mathrm{C}_{6} \mathrm{H}_{6}$ according to the last published WHO recommendations [4], however the European Air Quality Directive guidelines [5] recommend an exposure limit of 1.6 parts per billion (ppb), and in France, which has very strict guidelines, the limit is $0.6 \mathrm{ppb}$ [6].

In the future, $A Q$ assessment should ideally be based on real-time monitoring of air pollutants with high spatial resolution [7], allowing pollution mapping and forecasting. This can only be satisfied by utilizing low-cost monitoring devices of small size. Szulczynski et al. [3] recently published a review of currently commercially available sensors for VOC detection in outdoor and indoor air, in which they concluded that current sensor technologies suffer from too high limit of detection or poor selectivity.

In a report by Spinelle et al. from 2017, commercially available portable low-cost sensors for VOCs were reviewed, and it was found that few sensors can detect $\mathrm{C}_{6} \mathrm{H}_{6}$ at the concentrations of relevance for $A Q$ monitoring [8], with most sensors showing detection limits that are at least one order of magnitude above the guideline levels. Some of these small sensors can reach a low $\mathrm{C}_{6} \mathrm{H}_{6}$ detection limit down to $0.5 \mathrm{ppb}$. Unfortunately, none of the sensors are selective to a particular VOC, making it impossible to distinguish, e.g., the $\mathrm{C}_{6} \mathrm{H}_{6}$ concentration. Some of the reviewed sensors also include a selective absorbing cartridge for benzene. Unfortunately, the best limit of detection for commercially available sensors selective to $\mathrm{C}_{6} \mathrm{H}_{6}$ was found to be $10 \mathrm{ppb}$ for the Ion Science Tiger Select (Ion Science, Great Britain).

Among state-of-the-art research studies on portable AQ sensors [9], there are reports of prototypes including gas sensitive field effect transistors based on silicon carbide (SiC-FETs) that allow detection of 1-3 ppb of $\mathrm{C}_{6} \mathrm{H}_{6}$ [10]. Both SiC-FETs [11] and metal-oxide based sensors [12] operated in Temperature Cycled Operation can yield selectivity to specified VOCs. A drawback of this approach is the required sampling time, which increases the response time. An approach to improve the detection limit even further is the use of pre-concentrators [13], in which the gas concentration is temporarily increased by adsorbing gas over a long time and then releasing it. A similar approach is used by Trzcinski et al., where a miniaturized photoionization detector is coupled to a specifically designed pre-concentrator with selective desorption of benzene [14]. However, also those approaches have a prolonged response time as a drawback.

A low cost, portable sensor capable of detecting benzene at $1 \mathrm{ppb}$ or lower concentrations would thus constitute a breakthrough in the field of air quality monitoring.

Using the unique properties of graphene as a transducer allows fabrication of sensor devices that can be used for gas detection where low concentrations can be detected, including air quality control for human health. Besides a high sensitivity, also interaction with specific target analytes and a good selectivity must be addressed to get a useful sensor device. It has already been shown that decoration of the graphene surface with metal/oxide nanoparticles can lead to a higher sensitivity and selectivity towards certain gases, e.g., nitrogen dioxide $\left(\mathrm{NO}_{2}\right), \mathrm{C}_{6} \mathrm{H}_{6}$ and $\mathrm{CH}_{2} \mathrm{O}[15,16]$. Using a "soft" decoration approach, the surface chemistry of the sensing layer could be modified without changing the transducer's electronic properties. In addition, zinc oxide ( $\mathrm{ZnO})$ fibers [17] and iron oxide $\left(\mathrm{Fe}_{3} \mathrm{O}_{4}\right)$ decorated multiwall carbon nanotubes [18] in combination with ultraviolet (UV) irradiation have shown sensitivity towards $\mathrm{C}_{6} \mathrm{H}_{6}$. However, poor reproducibility and insufficient detection limits make the state-of-the-art sensors ill-suited for human safety applications. So far, these sensors were able to detect the mentioned gases down to tens of ppb, but not reliably lower. In this paper, which is an extension of a conference contribution [19], we demonstrate how it is possible to detect even single 
ppb concentrations, and we further introduce a data evaluation approach allowing fast response times to meet the criteria for AQ monitoring.

\section{Materials and Methods}

\subsection{Sensing Layer Preparation}

The graphene was grown epitaxially on silicon carbide $(\mathrm{SiC})$ through a sublimation process were an on-axis, semi-insulating (0001) $4 \mathrm{H}-\mathrm{SiC}$ substrate $(7 \mathrm{~mm} \times 7 \mathrm{~mm})$ is used for the formation of graphene in argon (Ar) at a temperature of $2000{ }^{\circ} \mathrm{C}$ and a pressure of $1 \mathrm{bar}$ [20]. The method allows a highly homogenous growth of monolayer graphene and requires no further transfer to another insulator. Hollow cathode pulsed plasma sputtering [21] was used to functionalize the graphene surface with iron oxide nanoparticles (NP).

\subsection{Characterization Techniques}

Before and after the deposition of nanoparticles, a series of characterization measurements was conducted to determine the graphene uniformity and quality, and to see if any damage of the graphene occurred during the deposition. Atomic Force Microscopy (AFM) (Quadrexed Dimension 3100 with a Nanoscope IVa controller) was used in tapping mode to obtain topography images of the sensing layers. The measurements were performed using silicon (Si) tips (PPP-NCHR-50 from Nanosensors) with a tip radius of curvature below $7 \mathrm{~nm}$. X-ray photoelectron spectroscopy (XPS) studies using a Microlab 310-F spectrometer were performed to investigate possible alterations made to the sample after deposition of NPs and to establish if $\mathrm{Fe}_{3} \mathrm{O}_{4}$ was present on the surface.

\subsection{Sensor Device Fabrication}

As a first step, titanium on gold $(\mathrm{Ti} / \mathrm{Au}, 2 / 200 \mathrm{~nm})$ contact pads were thermally evaporated onto the epitaxially grown graphene on $\mathrm{SiC}(\mathrm{EG} / \mathrm{SiC})$ before functionalization. The contacts have a size of $1 \mathrm{~mm} \times 1 \mathrm{~mm}$ with a distance of $1 \mathrm{~mm}$ between them. The sensor chip and a Pt-100 resistance thermometer were glued (Aremco Ceramabond 571) onto a ceramic heater (Heraeus $\mathrm{GmbH}$ ) to enable a controlled temperature loop, and welded to a 16 pin TO8 header to establish the electrical contacts. This device was mounted on top of a TO8-socket and connected to its pins using gold-wire bonding and silver glue (Epotek E3081). The final sensor was placed in a flow chamber connected to a gas mixing setup. A Keithley 2601B SourceMeter was used in a two-wire mode to measure the resistance between the contacts during gas exposure. The total gas flow was kept constant at $100 \mathrm{~mL} / \mathrm{min}$, and a dry mixture of $80 \% \mathrm{~N}_{2}$ and $20 \% \mathrm{O}_{2}$ was used as a purging and carrier gas. A more detailed description of the measurement system can be found in a previous work [22].

\subsection{Theoretical Approach}

The adsorption of gas molecules $\left(\mathrm{C}_{6} \mathrm{H}_{6}\right.$ and $\left.\mathrm{CH}_{2} \mathrm{O}\right)$ on pristine $\mathrm{EG}(\mathrm{PEG})$ and $\mathrm{Fe}_{3} \mathrm{O}_{4}$-decorated epitaxial graphene (DEG) on Si-face $4 \mathrm{H}-\mathrm{SiC}$ was investigated based on hybrid gas-phase density functional theory (DFT) calculations performed by using Gaussian 16 Rev. B.01 program package [23]. As a model of PEG, $4 \times 5$ first graphene layer located above $4 \times 5$ buffer layer, which is covalently bonded to $4 \times 4$ Si-face surface of hexagonal $\mathrm{SiC}$, has been chosen. DEG was simulated by full geometrical optimization of $\mathrm{Fe}_{3} \mathrm{O}_{4}$ located on PEG. All dangling bonds are passivated by the hydrogen atoms. The calculations were carried out using M06-2X level of theory with consideration of split basis set [24]. It is important to note that the dispersion-corrected DFT functional M06-2X includes implicitly modified parameters associated with the Hartree-Fock exchange interaction, thereby allowing prediction of the weak van der Waals interaction [25]. A 6-31G basis set was used for carbon $(\mathrm{C})$, silicon $(\mathrm{Si})$, oxygen $(\mathrm{O})$ and hydrogen $(\mathrm{H})$ atoms, while a LANL2DZ (Los Alamos National Laboratory 2 Double-Zeta) basis set was utilized for Fe species [26]. All atoms 
were enabled to be fully relaxed during geometrical optimization. All calculations were carried out without symmetry restrictions.

The adsorption energy of gas molecules $\left(E_{\mathrm{ads}}\right)$ was calculated by using the following Equation:

$$
E_{\mathrm{ads}}=\left(E_{\mathrm{tot}}^{\mathrm{PEG} / \mathrm{DEG}}+E_{\mathrm{tot}}^{\mathrm{gas}}\right)-E_{\mathrm{tot}}^{\mathrm{gas} @ P E G / D E G}
$$

where $E_{\text {tot }}^{\mathrm{PEG} / \mathrm{DEG}}$ and $E_{\text {tot }}^{\text {gas }}$ are the total energies of isolated templates and gas molecules $\left(\mathrm{C}_{6} \mathrm{H}_{6}\right.$ or $\mathrm{CH}_{2} \mathrm{O}$ ), respectively, whereas $E_{\text {tot }}^{\text {gas } @ P E G / D E G ~ i s ~ t h e ~ t o t a l ~ e n e r g y ~ o f ~ t h e ~ P E G ~ o r ~ D E G ~ a f t e r ~ c o m p l e x a t i o n ~}$ with gas molecules. Counterpoise correction for basis set superposition error (BSSE) [27] was applied for accurate prediction of the adsorption energy.

\section{Results and Discussions}

\subsection{Morphological and Structural Characterization}

Figure 1 shows AFM graphs of the graphene sensor surface before (a) and after (b) decoration with $\mathrm{Fe}_{3} \mathrm{O}_{4}$ NPs. Neglecting the characteristic steps corresponding to the $\mathrm{SiC}$ step bunching (typically $0.5-1.5 \mathrm{~nm}$ in height), the as-grown graphene surface in Figure 1a shows almost no roughness (Rq $\approx 0.25 \mathrm{~nm}$ on the terraces). The particle coverage is about $60 \%$, and single particles have an average diameter of about $80 \mathrm{~nm}$. The histogram in Figure 1c shows the width distribution for single particles and particle clusters. The main peaks arise for particles between 70 and $90 \mathrm{~nm}$, but also much larger agglomerates up to $290 \mathrm{~nm}$ can be seen. Raman spectroscopy confirms structural integrity of the graphene surface also after the decoration [16].

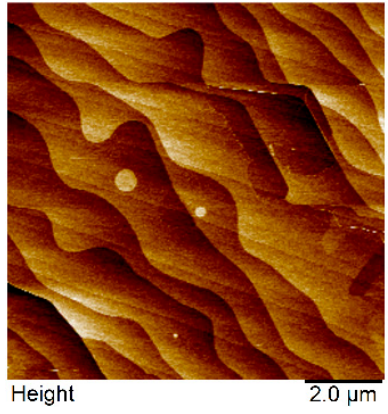

(a)

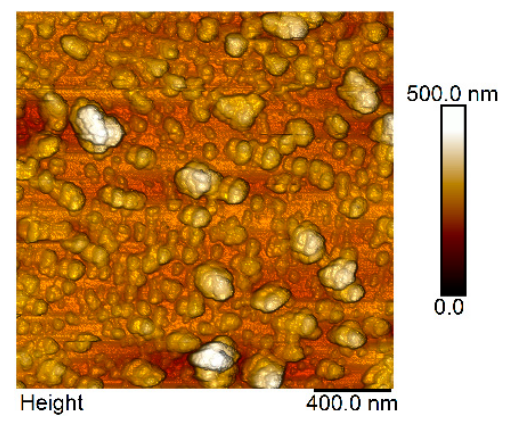

(b)

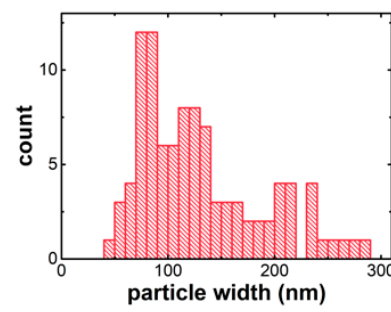

(c)

Figure 1. Atomic Force Microscopy (AFM) image of the graphene sensor surface before (a) and after (b) decoration with $\mathrm{Fe}_{3} \mathrm{O}_{4}$ NPs, and (c) the particle width distribution.

The effect of deposition of $\mathrm{Fe}_{3} \mathrm{O}_{4}$ NPs onto graphene was investigated by means of XPS. The elemental compositions of as-grown EG/SiC prior to and after deposition of $\mathrm{Fe}_{3} \mathrm{O}_{4} \mathrm{NPs}$ $\left(\mathrm{Fe}_{3} \mathrm{O}_{4} / \mathrm{EG} / \mathrm{SiC}\right)$ were obtained to demonstrate the presence of $\mathrm{Fe}_{3} \mathrm{O}_{4}$ NPs on the latter sample. The XPS survey spectra for $\mathrm{EG} / \mathrm{SiC}$ sample and $\mathrm{Fe}_{3} \mathrm{O}_{4} / \mathrm{EG} / \mathrm{SiC}$ sample are shown in Figure 2a. The XPS survey spectrum for $\mathrm{Fe}_{3} \mathrm{O}_{4} / \mathrm{EG} / \mathrm{SiC}$ showed the presence of iron and gold (Au) with XPS peaks Fe2p, Au4d, and Au4f found at binding energy position about $711 \mathrm{eV}, 340 \mathrm{eV}$ and $84 \mathrm{eV}$ [28]. The gold peaks in the XPS spectra come from the Ti/Au contacts (see Section 2.3). Both samples also showed the presence of oxygen, carbon, and silicon, see Figure 2 with XPS peaks O1s, C1s, Si2s and Si2p at binding energy positions about $532 \mathrm{eV}, 285 \mathrm{eV}, 151 \mathrm{eV}$ and $100 \mathrm{eV}$ respectively. XPS O1s, Fe2p, and $\mathrm{C} 1 \mathrm{~s}$ core level spectra for EG/SiC and $\mathrm{Fe}_{3} \mathrm{O}_{4} / \mathrm{EG} / \mathrm{SiC}$ are shown in Figure $2 \mathrm{~b}-\mathrm{d}$. Quantification of oxygen and carbon content for $\mathrm{EG} / \mathrm{SiC}$ and $\mathrm{Fe}_{3} \mathrm{O}_{4} / \mathrm{EG} / \mathrm{SiC}$, based on the XPS O1s and C1s core level spectra has been performed. An increase of $\mathrm{O}$, estimated to be a fivefold increase, and a decrease of $\mathrm{C}$, reduced to about half for $\mathrm{Fe}_{3} \mathrm{O}_{4} / \mathrm{EG} / \mathrm{SiC}$, were observed. The strong increase in oxygen signal is shown for $\mathrm{Fe}_{3} \mathrm{O}_{4} / \mathrm{EG} / \mathrm{SiC}$ sample, with an additional peak at binding energy position $530.0 \mathrm{eV}$, in good agreement with the presence of the chemical structure Fe-O in $\mathrm{Fe}_{3} \mathrm{O}_{4}$ NPs. XPS Fe2p core level 
spectra before and after deposition of $\mathrm{Fe}_{3} \mathrm{O}_{4}$ NPs are shown in Figure 2c. As expected, no iron could be detected for EG/SiC. After deposition, two strong peaks at binding energy position $710.9 \mathrm{eV}$ and $724.4 \mathrm{eV}$ were observed for $\mathrm{Fe}_{3} \mathrm{O}_{4} / \mathrm{EG} / \mathrm{SiC}$. The corresponding XPS C1s core level spectra for EG/SiC and $\mathrm{Fe}_{3} \mathrm{O}_{4} / \mathrm{EG} / \mathrm{SiC}$ are presented in Figure 2d.

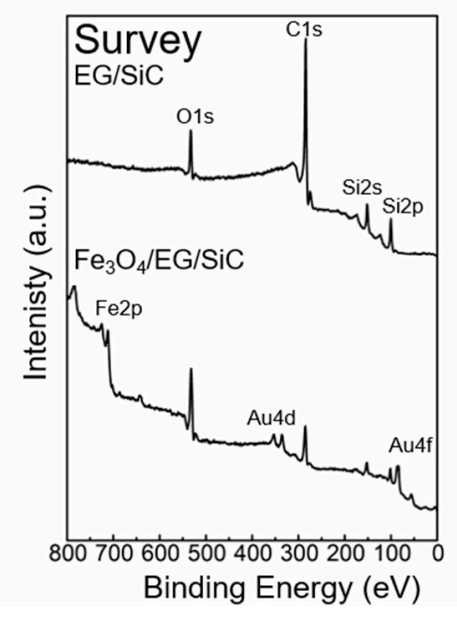

(a)

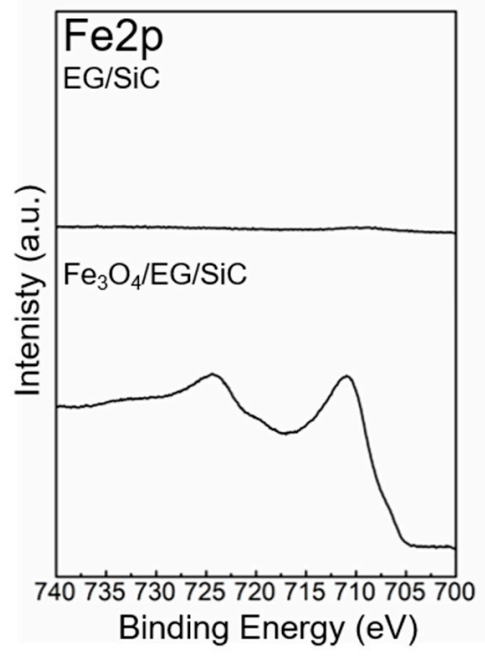

(c)

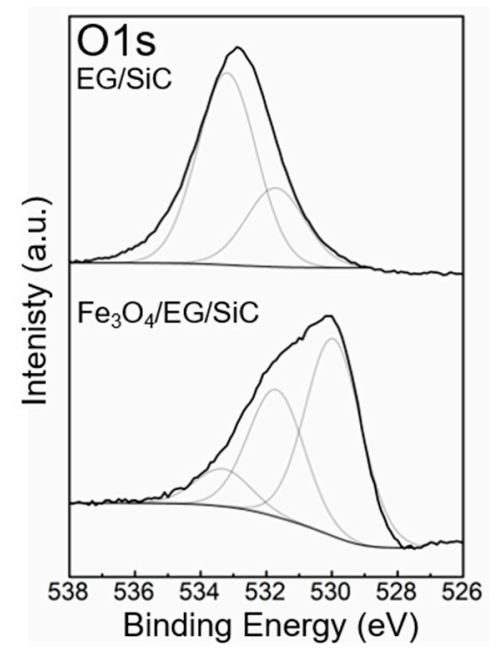

(b)

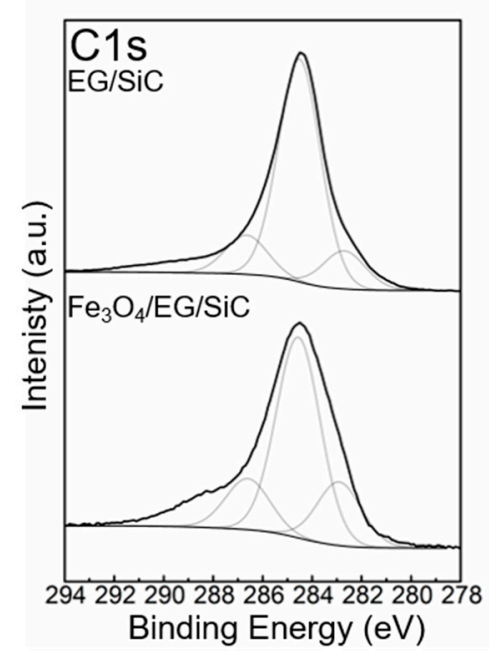

(d)

Figure 2. X-ray photoelectron spectroscopy (XPS) survey spectra (a), O1s (b), Fe2p (c) and C1s (d) XPS core level spectra for as-grown $\mathrm{EG} / \mathrm{SiC}$ and $\mathrm{Fe}_{3} \mathrm{O}_{4} \mathrm{NP}$ deposited on graphene $\left(\mathrm{Fe}_{3} \mathrm{O}_{4} / \mathrm{EG} / \mathrm{SiC}\right)$.

\subsection{Gas Measurements}

After the successful decoration of the graphene surface with $\mathrm{Fe}_{3} \mathrm{O}_{4} \mathrm{NPs}$, gas measurements were performed. Figure 3 a shows how the resistance of the sensor changes with the exposure towards $\mathrm{CH}_{2} \mathrm{O}_{\text {. }}$ The sensor was exposed to $\mathrm{CH}_{2} \mathrm{O}$ and $\mathrm{C}_{6} \mathrm{H}_{6}$ in a dry background of synthetic air using concentrations ranging from 5 parts per million $(\mathrm{ppm})$ to $1 \mathrm{ppb}$, and a pulse duration of $30 \mathrm{~min}$. Tests to identify a good operating temperature have been conducted and $150^{\circ} \mathrm{C}$, which is a good compromise between stability and high response, was chosen for all measurements shown here. Similar measurements with pure graphene did not show any response to both test gases. In an earlier work of ours [16], it has already been shown that $\mathrm{Fe}_{3} \mathrm{O}_{4}$ nanoparticle-decorated graphene sensors can be used for formaldehyde and benzene detection, but not over such a large range and down to a single ppb. The same measurement was repeated twice in the same environment and was repeated once more approximately one year later 
with the same sensor. The measured responses show some small deviations between the measurements without a clear trend of decreasing response over time. The sensor response shown here is from the first measurement. The response is defined as $\frac{R-R_{0}}{R_{0}}$, where $R$ is the saturated resistance signal and $R_{0}$ corresponds to the baseline resistance before the gas exposure. The raw sensor signal in Figure $3 a$ shows that the sensor does relax completely, but a slow drift hinders the baseline resistance to stay stable over time. DFT calculations support the choice of operating temperature, as they show that it is possible to overcome the desorption barrier of $\mathrm{C}_{6} \mathrm{H}_{6}$ at the sensor surface at $150{ }^{\circ} \mathrm{C}$ (see Figure $\mathrm{S} 1)$. The relative response for different concentrations of the two target gases is shown in Figure $3 \mathrm{~b}$. A distinct response for both gases over the whole range can clearly be observed. Both formaldehyde and benzene can be quantitatively measured down to a single ppb. The relative responses towards 1 ppb $\mathrm{CH}_{2} \mathrm{O}$ and $\mathrm{C}_{6} \mathrm{H}_{6}$ are about $0.04 \%$ and $0.02 \%$, respectively. It is worth to be noticed that the WHO recommended safety limit for $\mathrm{CH}_{2} \mathrm{O}$ (81 ppb over 30 min of exposure) is easily reached with a relative response above $0.1 \%$.

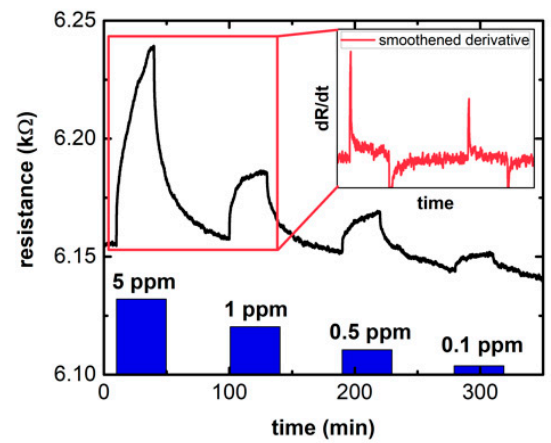

(a)

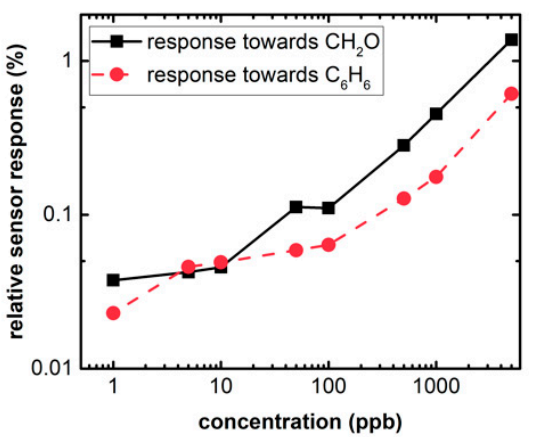

(b)

Figure 3. (a) Sensor behavior exemplarily shown for the first four exposures (5 ppm-0.1 ppm, $30 \mathrm{~min}$ exposure and relaxation) towards formaldehyde at $150{ }^{\circ} \mathrm{C}$ in dry air with the smoothened derivative signal as inset and (b) relative sensor response towards different concentrations of formaldehyde and benzene.

Besides a very good sensitivity, also time constants of these measurements need to be addressed. For an application in indoor air monitoring, the time constants for the sensor should be in the range of half a minute to several minutes, depending on the application. However, as shown in Figure 3a, even an exposure towards the gas over $30 \mathrm{~min}$ does not lead to a saturated sensor response. Using the time it takes for the first order time derivative of the sensor signal to reach its maximum for each exposure instead, the time constant can be decreased significantly. This is exemplarily shown for the first two exposures in the inset in Figure 3a, comparing the raw sensor signal with $d R / d t$ (after smoothening the data with a 500-point moving average filter), where the time derivative signal reaches its maximum value after about $50 \mathrm{~s}$. It is evident from the insert that $d R / d t$ exhibits distinct peaks in response to $\mathrm{CH}_{2} \mathrm{O}$ and the peak values are concentration dependent. Because of the smaller time constants needed to reach maximum $d R / d t$, the actual sensor signal does not have to be saturated when using the rate of change instead of the absolute value of resistance. It is therefore possible to significantly improve the speed of the sensor by utilizing $d R / d t$ as a sensor parameter.

\subsection{DFT Calculations}

An efficiency of the decoration approach towards gas sensing can be directly demonstrated and validated by the DFT results. For this aim, a comparative analysis of the adsorption of benzene and formaldehyde onto non-decorated and $\mathrm{Fe}_{3} \mathrm{O}_{4}$-decorated epitaxial graphene was performed. Energetically favored adsorption configurations of considered gas molecules on PEG and DEG are illustrated in Figure 4. The adsorption energy for $\mathrm{C}_{6} \mathrm{H}_{6}$ on DEG, $E_{\mathrm{ads}}=1.795 \mathrm{eV}$, is significantly higher than on PEG with a value of $E_{\text {ads }}=0.284 \mathrm{eV}$. In the absence of the $\mathrm{Fe}_{3} \mathrm{O}_{4}$ nanoparticle, $\mathrm{C}_{6} \mathrm{H}_{6}$ molecule 
adsorbs in the flat geometry, which is parallel to the surface. In this case, the center of $\mathrm{C}_{6} \mathrm{H}_{6}$ ring lays on top of a carbon atom belonging to graphene. On the other hand, a functionalization of graphene with $\mathrm{Fe}_{3} \mathrm{O}_{4}$ causes the formation of a strong chemical bond between $\mathrm{C}_{6} \mathrm{H}_{6}$ ring and one of the $\mathrm{Fe}$ atoms, facilitating the $\mathrm{C}_{6} \mathrm{H}_{6}$ adsorption in the tilted geometry regarding the graphene surface. Like the situation for $\mathrm{C}_{6} \mathrm{H}_{6}$, we found that $\mathrm{CH}_{2} \mathrm{O}$ molecule prefers to accommodate in a parallel geometry to graphene surface with weak adsorption energy of $0.149 \mathrm{eV}$, while the energetically preferred adsorption mode for $\mathrm{CH}_{2} \mathrm{O}$ on DEG is related to the formation of strong Fe-O covalent bond with a bond length of the $1.98 \AA$. The calculated adsorption energy of $1.870 \mathrm{eV}$ is much higher than the value predicted for adsorption on pristine graphene sample, implying the strong chemisorption case. To summarize, one can conclude that weak physisorption of gas molecules on non-decorated graphene is immediately changed to strong chemisorption when iron oxide NPs are involved in adsorption phenomena. From an experimental point of view, the observed chemical similarity between adsorption configurations of benzene and formaldehyde enables us to anticipate comparable responses of $\mathrm{Fe}_{3} \mathrm{O}_{4}$-decorated epitaxial graphene to exposure of both gases, with slightly higher sensitivity towards formaldehyde.

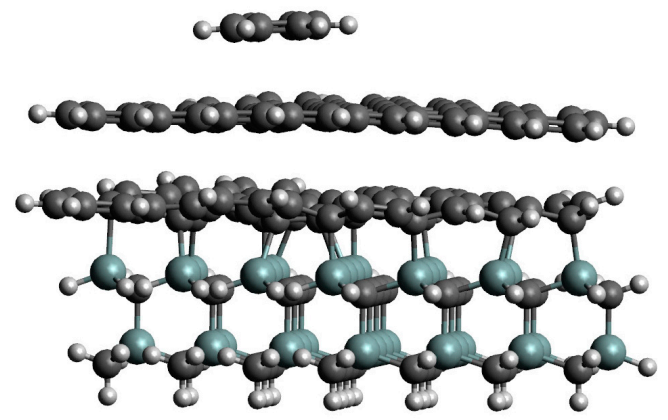

(a)

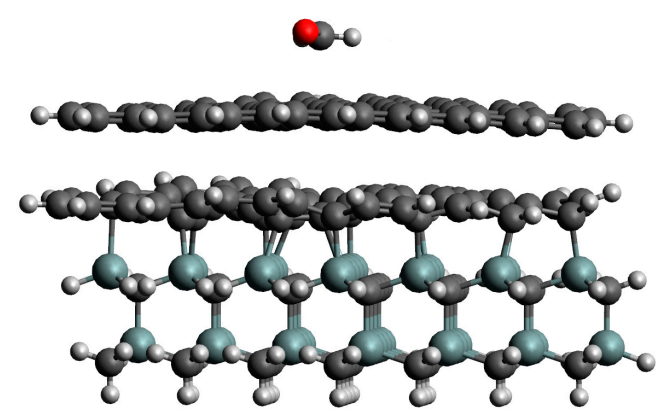

(c)

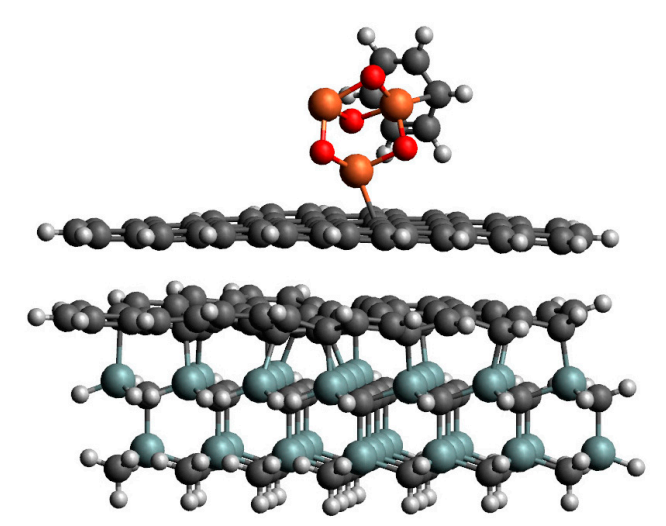

(b)

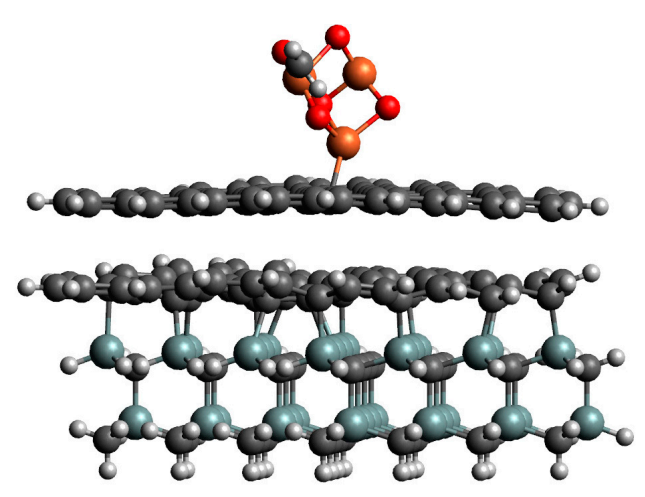

(d)

Figure 4. Optimized adsorption configurations of benzene on (a) PEG and (b) DEG. Preferred adsorption geometries of formaldehyde on PEG and DEG are presented as (c) and (d).

\section{Conclusions}

Benzene and Formaldehyde sensing properties were investigated using epitaxially grown graphene on silicon carbide decorated with $\mathrm{Fe}_{3} \mathrm{O}_{4}$ NPs. We could verify the decoration and the integrity of the graphene surface using AFM and XPS. With this sensor platform, concentrations down to a single ppb of toxic VOCs could be quantitatively measured, which makes it very promising for air quality monitoring. DFT calculations show that the gas molecules are more likely to bind to the decorated sensor surface. Moreover, by evaluating the first-order time derivative of the sensor signal, 
it was possible to significantly enhance the speed of the sensor, yielding response times of less than one minute, in turn allowing sampling rates desired in air quality monitoring.

Supplementary Materials: The following are available online at http:/ /www.mdpi.com/1424-8220/19/4/918/s1, Figure S1: Reaction energy profile corresponding to benzene desorption. IS, TS and FS represent the initial state, transition state and final state, respectively.

Author Contributions: Conceptualization, M.R., D.P. and J.E.; methodology, M.R., A.S. (Andreas Skallberg), S.E. and I.S.; software, I.S.; validation, M.R. and I.S.; formal analysis, M.R., A.S. (Andreas Skallberg) and I.S.; investigation, M.R., A.S. (Andreas Skallberg) and I.S.; resources, A.S. (Andreas Schütze); data curation, M.R., A.S. (Andreas Skallberg) and I.S.; writing-original draft preparation, M.R., A.S. (Andreas Skallberg) and I.S.; writing-review and editing, M.R., D.P., S.E., U.H., I.S., R.Y., A.S. (Andreas Skallberg), K.U., A.S. (Andreas Schütze) and J.E.; visualization, M.R., A.S. (Andreas Skallberg) and I.S.; supervision, J.E.; project administration, J.E.; funding acquisition, J.E.

Funding: This research was funded by the Swedish Foundation for Strategic research (SSF) for financial support through the grants GMT14-0077 and RMA15-024, and Knut and Alice Wallenberg Foundation through grant KAW14.0276. This work has been supported by The Centre in Nano science and technology (CeNano) through the project "Graphene-nanoparticle hybrid gas sensor" and the Swedish Government Strategic Research Area in Materials Science on Functional Materials at Linköping University (Faculty Grant SFO-Mat-LiU \#2009-00971), the Knut and Alice Wallenberg Foundation through Grant No. 2012.0083. I.S. acknowledges the support from Ångpanneföreningens Forskningsstiftelse (Grant 16-541). The research part in Germany was financed by a Hans Werthén Foundation grant.

Acknowledgments: The authors would like to thank Anita Lloyd Spetz and Manuel Bastuck for valuable discussion and support. DFT calculations were performed using the supercomputer resources of the Swedish National Infrastructure for Computing (SNIC), National Supercomputing Center (NSC).

Conflicts of Interest: The authors declare no conflict of interest.

\section{References}

1. WHO Social Media Toolkit for Air Pollution and Child Health: Prescribing Clean Air Launch. Available online: https://www.who.int/ceh/publications/Social_Media_Toolkit_AirPollution_Chidren_Health_ Report_Launch.pdf (accessed on 21 February 2019).

2. Economic Cost of the Health Impact of Air Pollution in Europe: Clean Air, Health and Wealth. Available online: http:/ / www.euro.who.int/_data/assets/pdf_file/0004/276772/Economic-cost-health-impactair-pollution-en.pdf (accessed on 21 February 2019).

3. Szulczyński, B.; Gębicki, J. Currently Commercially Available Chemical Sensors Employed for Detection of Volatile Organic Compounds in Outdoor and Indoor Air. Environments 2017, 4, 21. [CrossRef]

4. World Health Organization. Guidelines for Indoor Air Quality: Selected Pollutants. Available online: http:/ / www.euro.who.int/_data/assets/pdf_file/0009/128169/e94535.pdf (accessed on 21 February 2019).

5. Directive 2008/50/EC of the European Parliament and of the Council of 21 May 2008 on Ambient Air Quality and Cleaner Air for Europe. Available online: http:/ / eur-lex.europa.eu/LexUriServ /LexUriServ.do?uri=OJ: L:2008:152:0001:0044:EN:PDF (accessed on 21 February 2019).

6. Décret no 2011-1727 du 2 Décembre 2011 Relatif aux Valeurs-Guides pour L'air Intérieur pour le Formaldéhyde et le Benzène. Available online: https:/ / www.legifrance.gouv.fr/eli/decret/2011/12/2/ 2011-1727/jo/texte (accessed on 21 February 2019).

7. Batterman, S.; Chambliss, S.; Isakov, V. Spatial resolution requirements for traffic-related air pollutant exposure evaluations. Atmos. Environ. 2014, 94, 518-528. [CrossRef] [PubMed]

8. Spinelle, L.; Gerboles, M.; Kok, G.; Persijn, S.; Sauerwald, T. Review of portable and low-cost sensors for the ambient air monitoring of benzene and other volatile organic compounds. Sensors 2017, 17, 1520. [CrossRef] [PubMed]

9. Schütze, A.; Baur, T.; Leidinger, M.; Reimringer, W.; Jung, R.; Conrad, T.; Sauerwald, T. Highly Sensitive and Selective VOC Sensor Systems Based on Semiconductor Gas Sensors: How to? Environments 2017, 4, 20. [CrossRef]

10. Puglisi, D.; Eriksson, J.; Bur, C.; Schuetze, A.; Lloyd Spetz, A.; Andersson, M. Catalytic metal-gate field effect transistors based on $\mathrm{SiC}$ for indoor air quality control. J. Sens. Sens. Syst. 2015, 4, 1-8. [CrossRef] 
11. Bur, C.; Bastuck, M.; Puglisi, D.; Schütze, A.; Lloyd Spetz, A.; Andersson, M. Discrimination and quantification of volatile organic compounds in the ppb-range with gas sensitive $\mathrm{SiC}-\mathrm{FETs}$ using multivariate statistics. Sens. Actuators B Chem. 2015, 214, 225-233. [CrossRef]

12. Leidinger, M.; Sauerwald, T.; Reimringer, W.; Ventura, G.; Schütze, A. Selective detection of hazardous VOCs for indoor air quality applications using a virtual gas sensor array. J. Sens. Sens. Syst. 2014, 3, 253-263. [CrossRef]

13. Leidinger, M.; Rieger, M.; Sauerwald, T.; Alépée, C.; Schütze, A. Integrated pre-concentrator gas sensor microsystem for ppb level benzene detection. Sens. Actuators B Chem. 2016, 236, 988-996. [CrossRef]

14. Trzciński, J.W.; Pinalli, R.; Riboni, N.; Pedrini, A.; Bianchi, F.; Zampolli, S.; Elmi, I.; Massera, C.; Ugozzoli, F.; Dalcanale, E. In Search of the Ultimate Benzene Sensor: The EtQxBox Solution. ACS Sens. 2017, 2, 590-598. [CrossRef]

15. Eriksson, J.; Puglisi, D.; Strandqvist, C.; Gunnarsson, R.; Ekeroth, S.; Ivanov, I.G.; Helmersson, U.; Uvdal, K.; Yakimova, R.; Lloyd Spetz, A. Modified Epitaxial Graphene on SiC for Extremely Sensitive and Selective Gas Sensors. Mater. Sci. Forum 2016, 858, 1145-1148. [CrossRef]

16. Rodner, M.; Bahonjic, J.; Mathisen, M.; Gunnarsson, R.; Ekeroth, S.; Helmersson, U.; Ivanov, I.G.; Yakimova, R.; Eriksson, J. Performance tuning of gas sensors based on epitaxial graphene on silicon carbide. Mater. Des. 2018, 153, 153-158. [CrossRef]

17. Gong, J.; Li, Y.; Chai, X.; Hu, Z.; Deng, Y. UV-light-activated ZnO fibers for organic gas sensing at room temperature. J. Phys. Chem. C 2010, 114, 1293-1298. [CrossRef]

18. Clément, P.; Hafaiedh, I.; Parra, E.J.; Thamri, A.; Guillot, J.; Abdelghani, A.; Llobet, E. Iron oxide and oxygen plasma functionalized multi-walled carbon nanotubes for the discrimination of volatile organic compounds. Carbon N. Y. 2014, 78, 510-520. [CrossRef]

19. Rodner, M.; Puglisi, D.; Ekeroth, S.; Helmersson, U.; Ivanov, I.G.; Yakimova, R.; Uvdal, K.; Schütze, A.; Eriksson, J. Iron Oxide Nanoparticle Decorated Graphene for Ultra-Sensitive Detection of Volatile Organic Compounds. Proceedings 2018, 2, 985. [CrossRef]

20. Yakimova, R.; Virojanadara, C.; Gogova, D.; Syväjärvi, M.; Siche, D.; Larsson, K.; Johansson, L. Analysis of the Formation Conditions for Large Area Epitaxial Graphene on SiC Substrates. Mater. Sci. Forum 2010, 645-648, 565-568. [CrossRef]

21. Pilch, I.; Söderström, D.; Hasan, M.I.; Helmersson, U.; Brenning, N. Fast growth of nanoparticles in a hollow cathode plasma through orbit motion limited ion collection. Appl. Phys. Lett. 2013, 103, 193108. [CrossRef]

22. Lloyd Spetz, A.; Andersson, M. Technology and Application Opportunities for SiC-FET Gas Sensors. In Solid State Gas Sensors_-Industrial Application; Fleischer, M., Lehmann, M., Eds.; Springer: Berlin/Heidelberg, Germany, 2012; pp. 189-214. ISBN 978-3-642-28092-4.

23. Available online: http:/ / gaussian.com/ citation/ (accessed on 22 February 2019).

24. Zhao, Y.; Truhlar, D.G. A new local density functional for main-group thermochemistry, transition metal bonding, thermochemical kinetics, and noncovalent interactions. J. Chem. Phys. 2006, 125, 194101. [CrossRef]

25. Zhao, Y.; Truhlar, D.G. The M06 suite of density functionals for main group thermochemistry, thermochemical kinetics, noncovalent interactions, excited states, and transition elements: Two new functionals and systematic testing of four M06-class functionals and 12 other function. Theor. Chem. Acc. 2008, 120, 215-241. [CrossRef]

26. Hay, P.J.; Wadt, W.R. Ab initio effective core potentials for molecular calculations. Potentials for K to Au including the outermost core orbitale. J. Chem. Phys. 1985, 82, 299-310. [CrossRef]

27. Boys, S.F.; Bernardi, F. The calculation of small molecular interactions by the differences of separate total energies. Some procedures with reduced errors. Mol. Phys. 1970, 19, 553-566. [CrossRef]

28. Wang, G.; Zhang, X.; Skallberg, A.; Liu, Y.; Hu, Z.; Mei, X.; Uvdal, K. One-step synthesis of water-dispersible ultra-small $\mathrm{Fe}_{3} \mathrm{O}_{4}$ nanoparticles as contrast agents for $\mathrm{T}_{1}$ and $\mathrm{T}_{2}$ magnetic resonance imaging. Nanoscale 2014, 6, 2953-2963. [CrossRef] [PubMed]

(C) 2019 by the authors. Licensee MDPI, Basel, Switzerland. This article is an open access article distributed under the terms and conditions of the Creative Commons Attribution (CC BY) license (http:/ / creativecommons.org/licenses/by/4.0/). 